\title{
Pop psychology and predatory journals
}

\author{
D. Robert Siemens, MD, FRCSC \\ CUAJ Editor-in-Chief and Department of Oncology, Queen’s University, Kingston, ON, Canada
}

Cite as: Can Urol Assoc J 2017; Epub ahead of print. http://dx.doi.org/10.5489/cuaj.4993

\section{Published online November 1, 2017}

$* * *$

I've been considering hinting to my kids that for the upcoming holidays, it would most welcome if they were to take wholesale control of my external electronic memory systems (email, Facebook, LinkedIn, Twitter, etc.) in order to revamp, reorganize, create rules, and declutter a part of my life that is becoming increasingly frustrating and obstructive to productivity. I know I'm not likely alone in this fantasy. Several of my colleagues have apparently initiated a friendly competition to see how many "unread" messages they can collect in their inbox: a somewhat perverse act of rebellion against the never-ending whims of the instantcommunication gods? Last I checked, the number of the front-runner was north of 2500.

Truth be told, this thought came about after re-skimming an interesting book entitled, “The Organized Mind,” by a cognitive psychologist from McGill named Daniel Levitin. ${ }^{1}$ The book serves up some self-help to all of us struggling with today's information deluge brought on both at work and play, and throws in enough neuroscience to satisfy those of us who carry a decent amount of suspicion for any pop psychology offerings. Whatever you think of the genre — and no disrespect to the author for the "pop" reference — the book makes several obvious but sobering points, including his estimate that today, we take in nearly five times the amount of information every day than we did 20 years ago (more than 34 gigabytes) and our brain can only process about 120 bits per second. We just don’t have the necessary RAM! After first reading the book a few years ago, I've tried to implement a few of the proffered strategies: daydreaming more and off-loading my schedule-making to others (both to the consternation of my wife and administrative assistants).

It turns out my kids are probably the least capable of contributing to this recent burst of organizational housekeeping: efficiently categorizing all electronic input for easier later access and action. They seem to be pleasantly egosyntonic with this attention-stealing information infestation and unwilling to consider that there is any problem. So, stuck with the job myself, the first step was to revisit those filter setups for my Outlook inbox to optimize the cull of the unrelenting junk mail that lands there every morning. It was during this recent attempt at purging that it hit home that the most indefatigable culprits were those from medical journals with the just slightly nonsensical names, such as the Journal of Clinical Andrology and Advanced Robotics. (I made this up after a brief check to make sure it hadn't been founded 
yet.) If readers of $C U A J$ have recently published any article or comment in a reputable journal, or even just accessed a manuscript from an online source, you likely have been similarly inundated with requests to visit a predatory journal's website and consider submitting an original paper or review article on a subject matter "around your honourable scientific expertise." As an aside, I've wondered why most of these predatory journals have slightly offkilter names and their pitches are composed with shockingly poor grammar. Perhaps, as suggested by Levitt and Dubner, the authors of "Freakonomics," ${ }^{2}$ schemes like this are built in such a way to filter out (and waste less time on) serious authors, researchers, and readers in order to focus their attention on those gullible (or desperate) enough to ignore the high likelihood that the journal's mission is for-profit only, with little regard to any academic integrity. Indeed, a friend recently quipped that he's considering diversifying his portfolio by establishing the International Journal of Left-sided Flank Pain.

This is obviously becoming a serious issue in our academic community. There are literally thousands of predatory journals whose sole purpose is to extract author fees with little or no editorial oversight, as peer-review is barely an afterthought. You may have come across a disturbing, but nonetheless fascinating article in Nature earlier this spring describing a sting on scientific journals to illustrate the extent of the problem. ${ }^{3}$ The authors from the University of Wroclaw in Poland created a fictitious and wholly inadequate scientist, with effectively no academic track record, named Anna O. Szust (Oszust is Polish for “a fraud”). They sent an application, including a dismal CV, for an editorial position to a mix of 360 reputable and potential predatory journals. They chose the journals from several well-known directories, including those designating an official impact factor, Journal Citation Reports (JCR), as well as the Directory of Open Access Journals (DOAJ) and the infamous and currently mothballed "Beall's list" of suspected predatory open-access journals. The results were remarkable. No JCR publisher took the bait, but 40 suspected predatory journals and eight DOAJ journals appointed her as an editor. A dozen journals accepted her as an editor conditional on some sort of payment and two offered her to start her own journal as lead editor. One of the excerpts from the email replies from the predatory journals stated, "It's our pleasure to add your name as our editor in chief with this journal with no responsibilities."

The extent of the problem is staggering. The number of suspected predatory journals has increased dramatically over the last few years, with nearly 10000 appearing on the "Biell's" blacklist in 2016 and over a half of million papers published. ${ }^{3}$ As one would suspect, the urological sciences are not immune. Di Lena and Nickel recently presented a similarly themed report of a single academic urologist's email requests for submissions to open-source journals. ${ }^{4}$ Over two-thirds were suspected to be predatory, with false claims of legitimacy and such poor journal metrics that it is highly unlikely any work would have been read or cited. Interestingly, the majority of publishers appeared to originate in the U.S. Beyond the waste of authors' time and resources, these predatory exploits threaten an important experiment with respect to biomedical research dissemination, that is, the legitimate open-source journal movement. 
Open-source journals have expanded dramatically over the last several years and, despite some initial reservation in the academic community, are playing a "disruptively" innovative role, with the ideals of publishing at lower costs and facilitating expanded, freely available access to the latest research. CUAJ is proudly committed to our open-access status.

The open-access paradigm is being co-opted and exploited by these predatory schemes. Thankfully, there are resources to help authors and readers wade through this mess, including the Urology Green List, easily found online and curated by respected leaders in our field to provide some guidance on both subscription and open-access journals. Thank you Henry Woo et al! Maybe you can start to work on a mechanism of helping us navigate the myriad of advertisements for medical conferences next. More time for daydreaming!

\section{References}

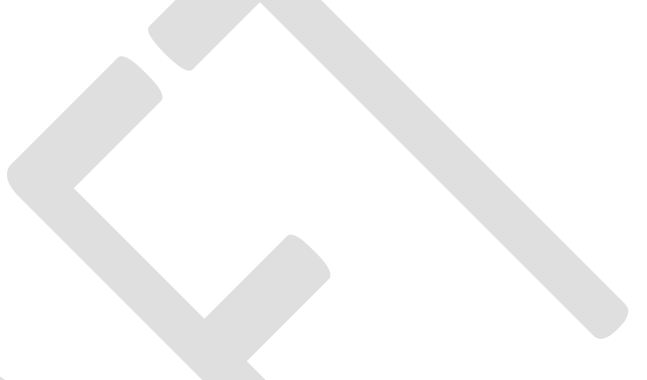

1. Daniel J. Levitin. The Organized Mind. Penguin Canada Books. 2014. Toronto, Canada.

2. Levitt SD, Dubner SJ. Think Like A Freak. Willam Morrow. 2014.

3. Pisanski K, Sorokowski P, Kulczycki E, et al: Predatory journals recruit fake editor. Nature 2017;543:481-3. https://doi.org/10.1038/543481a

4. DiLena M, Nickel JC. Publish or/and perish. Can Urol Assoc J 2017;11(9Suppl6):S305-58. Abstract P98. http://dx.doi.org/10.5489/cuaj.4896. 